\title{
ChemComm
}

\section{First synthesis and aggregation behaviour of periconjugated triazoliumfullerene $\dagger$}

Cite this: Chem. Commun., 2014 50, 581

Received 29th July 2013,

Accepted 20th October 2013

DOI: $10.1039 / c 3 c c 45783 d$

www.rsc.org/chemcomm

\author{
Naohiko Ikuma, * Saori Inaba, Ken Kokubo and Takumi Oshima
}

\begin{abstract}
Triazoliumfullerene was first prepared by the [3+2] cycloaddition of in situ generated 1,3-diaza-2-azoniaallene with fullerene and was characterized by the dispersed positive charge over the fullerene sphere associated with periconjugation. This new type of amphiphilic fullerene tended to form vesicles and crystalline aggregates after the casting of THF or MeOH solutions.
\end{abstract}

Ionic fullerenes ${ }^{1-6}$ are useful compounds for medical applications such as in antibacterial ${ }^{1 f}$ and anti-HIV ${ }^{1 g}$ agents, and also for selfassembling nanocarbon materials ${ }^{2,3}$ owing to the presence of amphiphilic intermolecular ionic, dipole-dipole, $\pi-\pi$ and hydrophobic interactions. These ionic and highly polar fullerenes are apt to form vesicle, ${ }^{1 h, 2,3}$ nanowire, ${ }^{1 h, 2,4}$ and nanosheet ${ }^{5}$ structures by way of self-assembly. Their aggregation behaviors highly depend on how the introduced ionic (hydrophilic) groups electronically affect the nonpolar (hydrophobic) fullerene cage. Here, it is interesting to know what kind of aggregation occurs if the ionic charge is dispersed on the $\pi$-conjugated fullerene cage. Such charge dispersion can be attained for the nitrogen incorporated $60 \pi$ ionic azafullerene $\left(\mathrm{C}_{59} \mathrm{~N}^{+}\right){ }^{6}$ However, the extremely low stability and intrinsic activity of reduction ${ }^{7}$ restricted its usual application as an ionic fullerene.

This situation prompted us to design a new type of ionic fullerene with possible conjugation; one promising candidate is through-space periconjugation ${ }^{8}$ between the outer ionic site and the $\pi$-conjugated fullerene cage. We have attempted the introduction of a cationic 1,2,3-triazolium unit ${ }^{9}$ into the fullerene sphere, because the possible high delocalization of positive charge on the $\mathrm{N}_{1}-\mathrm{N}_{2}-\mathrm{N}_{3}$ linkage will allow direct electron withdrawal as well as possible periconjugation with the adjacent fullerene cis- $1 \pi$-orbital. By DFT calculations, ${ }^{10}$ it was found that the LUMO of the triazoliumfullerene was delocalized both on the cationic

Division of Applied Chemistry, Graduate School of Engineering, Osaka University, Suita, Osaka 565-0871, Japan. E-mail: ikuma@chem.eng.osaka-u.ac.jp

$\dagger$ Electronic supplementary information (ESI) available: Synthesis, ${ }^{1} \mathrm{H} /{ }^{13} \mathrm{C}$ NMR charts (with DFT simulation) and magnified SEM/TEM images of $3^{+}$, and calculated TS coordinates. See DOI: 10.1039/c3cc45783d
$\mathrm{N}_{1}-\mathrm{N}_{2}-\mathrm{N}_{3}$ linkage and the fullerene cage (Fig. 1a and b), and the LUMO level was $0.36 \mathrm{eV}$ lower than that of pyrrolidiniumfullerene (Fig. 1d and e), ${ }^{1 a-d, 2,5 a}$ a typical ammonium fullerene. Moreover, in the electrostatic potential (ESP) map of pyrrolidiniumfullerene, the positive site is apparently localized on the pyrrolidinium moiety (blue on the ESP map in Fig. 1f) and the fullerene sphere remains in a less charged state. By contrast, the ESP map of triazoliumfullerene shows a considerable distribution of positive charge over the fullerene cage with an ambiguous boundary (Fig. 1c), whereby its dipole moment is smaller than that of pyrrolidiniumfullerene. Therefore, triazoliumfullerene (as a salt) is expected to behave as a unique amphiphile in contrast to the previously employed ionic fullerenes. In this communication,

\section{Triazoliumfullerene (Fullerotriazolium)}

a)

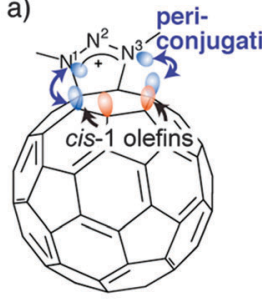

b)
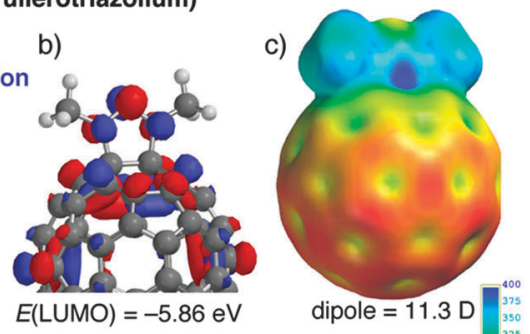

Pyrrolidiniumfullerene (Fulleropyrrolidinium)

d)

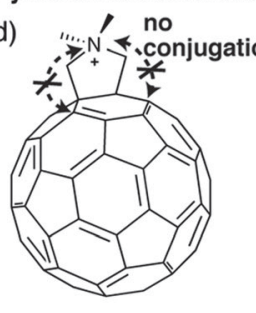

e)
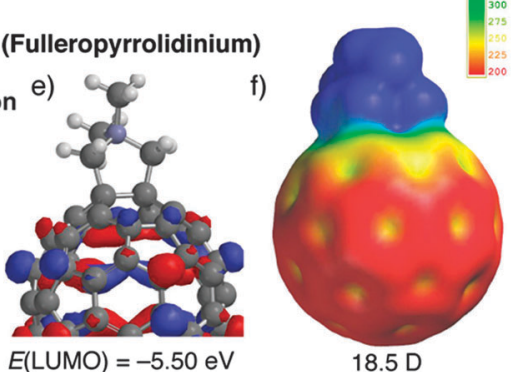

Fig. 1 Comparative representation of triazoliumfullerene and pyrrolidiniumfullerene: $(a, d)$ molecular structure, $(b, e)$ LUMO with its levels shown, $(c, f)$ electrostatic potential (ESP) maps of the electron density contours and dipole moments with a color bar of ESP energy $\left(\mathrm{kJ} \mathrm{mol}^{-1}\right)$; i.e., blue is more electropositive (cationic) while red is lower (relatively apolar). DFT calculations were carried out with the B3LYP/6-31G(d) level of theory. 


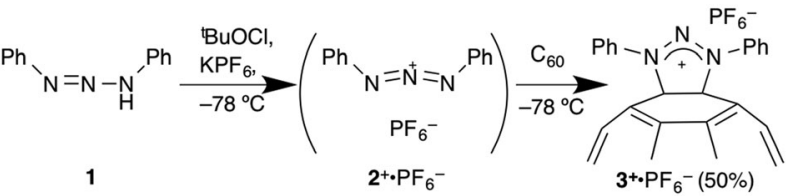

$$
\begin{aligned}
& \text { Scheme } 1
\end{aligned}
$$

we report the one-pot first synthesis of triazoliumfullerene (as a $\mathrm{PF}_{6}$ salt), theoretical calculation of the mechanistic pathway, and preliminary DLS/SEM/TEM measurements of its self-aggregation.

To prepare triazoliumfullerene, we employed [3+2] cycloaddition $^{9}$ of 1,3-diaza-2-azoniaallene salt $2^{+}$with fullerene as a $2 \pi$ component. The intermediate $2^{+}$was generated in situ via sequential chlorination and ionization of commercially available diphenyltriazene $\mathbf{1}$ by tert-butyl hypochlorite and the Lewis acid $\mathrm{KPF}_{6}{ }^{11}$ at $-78{ }^{\circ} \mathrm{C}$. To avoid spontaneous decomposition of the unstable intermediate $2^{+}$, a one-pot reaction was carried out with $\mathrm{C}_{60}$ at $-78{ }^{\circ} \mathrm{C}$ to give 1,3-diphenyltriazoliumfullerene salt $3^{+} \cdot \mathrm{PF}_{6}{ }^{-}$ (Scheme 1). The ${ }^{13} \mathrm{C}-\mathrm{NMR}$ measurement showed $\mathrm{ca} .16$ peaks of $\mathrm{sp}^{2}$-fullerene carbons (and 4 phenyl peaks, Fig. S1 in the ESI $\dagger$ ) and one $\mathrm{sp}^{3}$ peak at $91 \mathrm{ppm}$, indicating the occurrence of $C_{2 \mathrm{v}}$ symmetric addition at the 6,6-bond of fullerene. The downfield shift of the $\mathrm{sp}^{3}$ carbon is probably because of the electron-withdrawal by the conjunct positive $\mathrm{N}_{1}$ and $\mathrm{N}_{2}$ atoms, which is in conformity with a computational simulation (96 ppm by a GIAO/B3LYP/6-31G(d) approach with IEFPCM/DMSO, Fig. S2 in the ESI $\dagger$ ). Unfortunately, however, such $C_{2 \mathrm{v}}$ peaks gradually disappeared with the addition of $\mathrm{D}_{2} \mathrm{O}$ into the NMR DMSO solution ( $c a .10 \% \mathrm{v} / \mathrm{v}$ ), while the addition of methanol- $d_{4}$ brought about no change in the spectra. This water degradation may be ascribed to the lower LUMO level of triazoliumfullerene ( $v s$. water persistent pyrrolidiniumfullerene), which would enhance the electrophilic activity.

The enhancement of the electron accepting ability of $3^{+}$was also confirmed by cyclic voltammetry (Fig. S3, ESI $\dagger$ ). The higher reducing potential of $3^{+}$(vs. $\mathrm{N}, \mathrm{N}$-dimethylpyrrolidiniumfullerene ${ }^{1 b, 2}$ ) is ascribed to the lower LUMO level due to the periconjugation. The irreversibility of the first peak may indicate the instability of the reduced intermediate. This higher electron accepting ability would lead to intensified n-type semiconductibility and $\pi$-soft Lewis acidity. ${ }^{12}$ Moreover, $3^{+}$seems to be a potential candidate for photoinduced electron-transfer materials if some donating counteranions or substituents are introduced.

Although the [3+2] cycloaddition of 1,3-diaza-2-azoniaallene salt with small alkenes was reported to proceed via a concerted pathway, ${ }^{9 d, 13}$ it is unclear whether this is also the case for the highly conjugated and strained alkenes like fullerenes. As indicated by DFT calculations $^{10}$ (BHandHLYP/6-31G(d) with IEFPCM (toluene)), ${ }^{13}$ the unusually low LUMO level $(-3.72 \mathrm{eV})$ of $2^{+}$is suitable for orbital interaction with the symmetry allowed HOMO $(-6.76 \mathrm{eV})$ of $\mathrm{C}_{60}$ (Fig. 2a and b). TS calculations clarified a concerted transition state with the extremely small activation energy of $1.4 \mathrm{kcal} \mathrm{mol}^{-1}$ (Fig. 2c and d) and almost equivalent $\mathrm{C}_{60}-\mathrm{N}$ distances (2.3963 and $2.3965 \AA$ ). Moreover, the calculation for the product $3^{+}$(Fig. S4 in the $\mathrm{ESI}^{\dagger}$ ) showed a $c a .1 .0 \mathrm{eV}$ lower HOMO level $(-7.79 \mathrm{eV})$ than that of $\mathrm{C}_{60}$, explaining the absence of bisadducts of $2^{+14}$ These theoretical

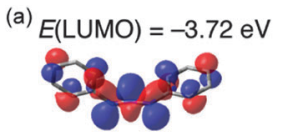

(b)

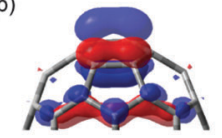

$E(\mathrm{HOMO})=-6.76 \mathrm{eV}$

(d)

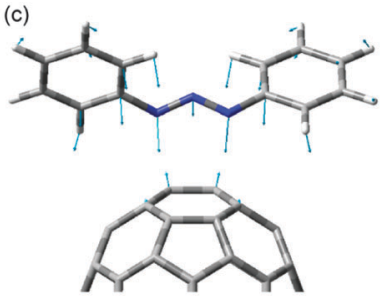

TS

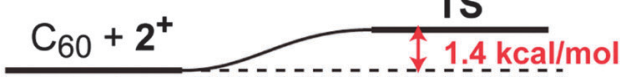

Fig. 2 (a) LUMO of $\mathbf{2}^{+}$(hydrogen omitted), (b) $\mathrm{HOMO}$ (in part) of $\mathrm{C}_{60}$, (c) transition state (TS) geometry and the vibrational vectors of imaginary frequency $\left(\nu_{\mathrm{i}}=-102.3 \mathrm{~cm}^{-1}\right)$, and (d) energy diagram (ZPE corrected) of the reaction. These calculations were carried out with the BHandHLYP/ $6-31 G(d)$ level of theory with solvent parameters (IEFPCM, toluene). ${ }^{13}$

results imply that the present $[3+2]$ reaction of $2^{+}$proceeds via a concerted process like 1,3-dipolar cycloaddition, although such HOMO controlled reactions of $\mathrm{C}_{60}$ are very rare on account of the inherent low LUMO level of fullerene. ${ }^{15}$

The self-assembly of triazoliumfullerene was assessed by dynamic light scattering (DLS) and scanning and transmission electron microscopy (SEM and TEM). The solvation of its $\mathrm{PF}_{6}$ salt in THF showed slight aggregation $\left(1 \times 10^{-5} \mathrm{M}, c a .100 \mathrm{~nm}\right.$ particle size, Fig. 3a). After casting of the solution on a Si-plate and evaporation, SEM images indicated both spherical and nanocrystalline self-assemblies (Fig. $3 \mathrm{~b}$ and Fig. S5a, ESI $\dagger$ ). For the solution with methanol, the ratio of nanocrystals/vesicles
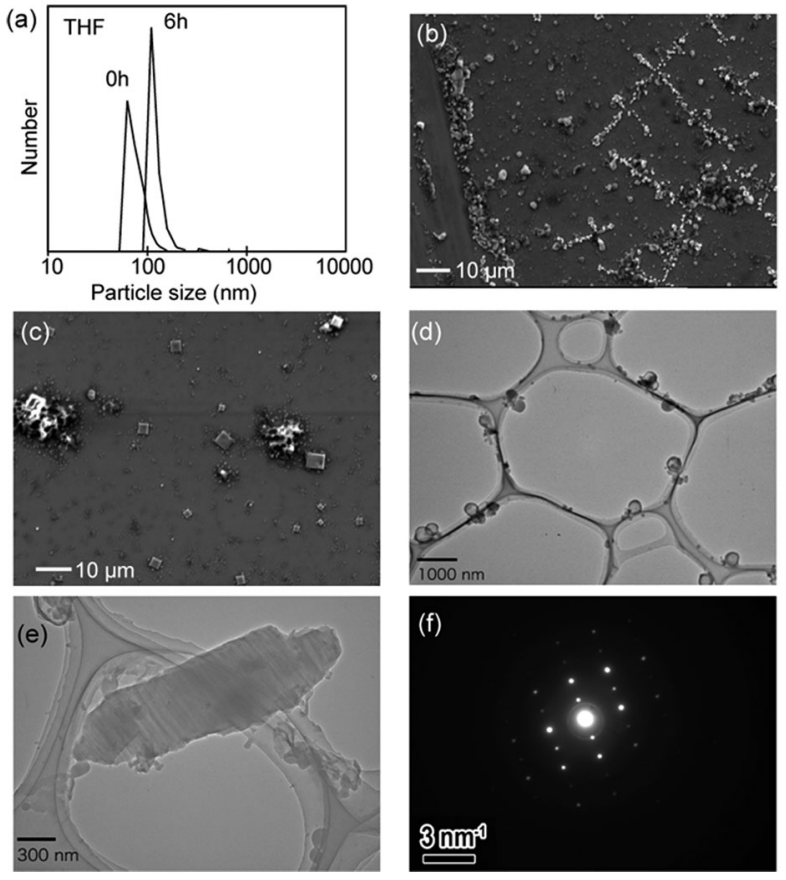

Fig. 3 Aggregation behaviour of $3^{+} \cdot \mathrm{PF}_{6}{ }^{-}$salt. (a) DLS measurement in THF solution. SEM image after casting (b) THF solution or (c) $\mathrm{MeOH}$ solution. (d) Vesicle and (e) microcrystal TEM images and (f) diffraction pattern after casting $\mathrm{MeOH}$ solution on a carbon/Cu microgrid. 
seems to increase (Fig. 3c). By TEM analysis, these spherical aggregates seem to be 100-300 $\mathrm{nm}$ vesicles with hollow centers (Fig. 3d and Fig. S5b, ESI $\dagger$ ), although the present experiments cannot unambiguously certify bilayer formation. Such vesicles have often been observed in ionic fullerenes. ${ }^{2,3}$ Interestingly, TEM also showed micrometer-scale crystals (Fig. 3e) with a clear diffraction pattern (Fig. 3f). Such microcrystals were occasionally observed in non-ionic supramolecular fullerenes with semiconductivity. ${ }^{16}$ Crystalline triazoliumfullerene can be useful for electron-transport materials with lower LUMO levels, although the configurational control of counteranions is required to inhibit the possible carrier-trapping.

Although the quantitative evaluation of periconjugative effects requires further experiments (e.g., with varying substituents and counteranions), we consider that the moderate amphiphilicity of $3^{+}$ with a small dipole moment $(\sim 11 \mathrm{D})$ and highly delocalized positive charge would be responsible for the simultaneous formation of vesicles and microcrystals. While pyrrolidiniumfullerene with a larger dipole $(\sim 18$ D) preferably aggregates in an antiparallel manner to form bilayers, ${ }^{1 i}$ the smaller dipole of triazoliumfullerene can exhibit another type of aggregation mode. In this case, the enhanced $\pi$-acceptor ability caused by the delocalized positive charge on the fullerene sphere may promote crystalline aggregation with the aid of counteranions as well as the aryl-substituents.

In conclusion, we first prepared triazoliumfullerene by a one-pot reaction of in situ generated 1,3-diaza-2-azoniaallene with $\mathrm{C}_{60}$ and confirmed the periconjugative delocalization of positive charge into the fullerene cage. This compound is expected to exhibit vesicle/crystalline self-assembly due to its moderate amphiphilic interactions and highly delocalized positive charge.

TEM measurements were carried out by using a piece of equipment in the Research Center for Ultrahigh Voltage Electron Microscopy, Osaka University. We thank Prof. Mikiji Miyata and Dr Ichiro Hisaki for the DLS measurements, Prof. Shu Seki for the SEM measurements, and Dr Keita Kobayashi for the TEM measurements. This work was partly supported by a Grant-in-Aid for Young Scientist (B) (No. 24750039) from JSPS and by Health Labour Sciences Research Grants from MHLW.

\section{Notes and references}

1 (a) R. Bullard-Dillard, K. E. Creek, W. A. Scrivens and J. M. Tour, Bioorg. Chem., 1996, 24, 376; (b) D. M. Guldi, H. Hungerbuhler and K. D. Asmus, J. Phys. Chem. A, 1997, 101, 1783; (c) A. M. Cassell, W. A. Scrivens and J. M. Tour, Angew. Chem., Int. Ed., 1998, 37, 1528; (d) K. Kordatos, T. Da Ros, S. Bosi, E. Vázquez, M. Bergamin, C. Cusan, F. Pellarini, V. Tomberli, B. Baiti, D. Pantarotto, V. Georgakilas, G. Spalluto and M. Prato, J. Org. Chem., 2001, 66, 4915; (e) S. Bosi, L. Feruglio, D. Milic and M. Prato, Eur. J. Org. Chem., 2003, 4741; $(f)$ T. Mashino, D. Nishikawa, K. Takahashi, N. Usui, T. Yamori, M. Seki, T. Endo and M. Mochizuki, Bioorg. Med. Chem. Lett., 2003, 13, 4395; (g) S. Bosi, T. Da Ros, G. Spalluto, J. Balzarini and M. Prato, Bioorg. Med. Chem. Lett., 2003, 13, 4437; (h) D. M. Guldi, F. Zerbetto, V. Georgakilas and M. Prato, Acc. Chem. Res., 2005, 38, 38; (i) C. J. Chancellor, A. A. Thorn, C. M. Beavers, M. M. Olmstead and A. L. Balch, Cryst. Growth Des., 2008, 8, 976.
2 (a) A. M. Cassell, C. L. Asplund and J. M. Tour, Angew. Chem., Int. Ed., 1999, 38, 2403; (b) V. Georgakilas, F. Pellarini, M. Prato, D. M. Guldi, M. Melle-Franco and F. Zerbetto, Proc. Natl. Acad. Sci. U. S. A., 2002, 99, 5075.

3 (a) S. Zhou, C. Burger, B. Chu, M. Sawamura, N. Nagahama, M. Toganoh, U. E. Hackler, H. Isobe and E. Nakamura, Science, 2001, 291, 1944-1947; (b) H. Isobe, T. Homma and E. Nakamura, Proc. Natl. Acad. Sci. U. S. A., 2007, 104, 14895.

4 P. Brough, D. Bonifazi and M. Prato, Tetrahedron, 2006, 62, 2110.

5 (a) T. Shiga and T. Motohiro, Thin Solid Films, 2007, 515, 3607; (b) K. Masuda, T. Abe, H. Benten, H. Ohkita and S. Ito, Langmuir, 2010, 26, 13472; (c) H. Li, M. J. Hollamby, T. Seki, S. Yagai, H. Möhwald and T. Nakanishi, Langmuir, 2011, 27, 7493.

6 (a) J. C. Hummelen, B. Knight, J. Pavlovich, R. Gonzalez and F. Wudl, Science, 1995, 269, 1554; (b) K. C. Kim, F. Hauke, A. Hirsch, P. D. W. Boyd, E. Carter, R. S. Armstrong, P. A. Lay and C. A. Reed, J. Am. Chem. Soc., 2003, 125, 4024; (c) O. Vostrowsky and A. Hirsch, Chem. Rev., 2006, 106, 5191.

7 Azafullerene is easily reduced to form a dimer, which is a reactive intermediate for further reactions. See (a) M. Keshavarz-K, R. Gonzalez, R. G. Hicks, G. Srdanov, V. I. Srdanov, T. G. Collins, J. C. Hummelen, C. Bellavia-Lund, J. Pavlovich, F. Wudl and K. Holczer, Nature, 1996, 383, 147; (b) N. B. Shustova, I. V. Kuvychko, A. A. Popov, M. von Delius, L. Dunsch, O. P. Anderson, A. Hirsch, S. H. Strauss and O. V. Boltalina, Angew. Chem., Int. Ed., 2011, 50, 5537.

8 (a) M. Eiermann, R. C. Haddon, B. Knight, Q. C. Li, M. Maggini, N. Martín, T. Ohno, M. Prato, T. Suzuki and F. Wudl, Angew. Chem., Int. Ed. Engl., 1995, 34, 1591; (b) B. Knight, N. Martín, T. Ohno, E. Ortí, C. Rovira, J. Veciana, J. Vidal-Gancedo, P. Viruela, R. Viruela and F. Wudl, J. Am. Chem. Soc., 1997, 119, 9871; (c) P. Ceroni, F. Conti, C. Corvaja, M. Maggini, F. Paolucci, S. Roffia, G. Scorrano and A. Toffoletti, J. Phys. Chem. A, 2000, 104, 156; (d) F. B. Kooistra, T. M. Leuning, E. Maroto-Martinez and J. C. Hummelen, Chem. Commun., 2010, 46, 2097.

9 (a) W. Wirschun and J. C. Jochims, Synthesis, 1997, 233; (b) W. Wirschun, G. M. Maier and J. C. Jochims, Tetrahedron, 1997, 53, 5755; (c) W. Wirschun, M. Winkler, K. Lutz and J. C. Jochims, J. Chem. Soc., Perkin Trans. 1, 1998, 1755; (d) M. Weng, A. Geyer, A. Friemel, J. C. Jochims and M. Lutz, J. Prakt. Chem., 2000, 342, 486.

10 In this paper, all DFT calculations were carried out with Spartan'08 or Gaussian 09. Full citations are shown in the ESI. $\dagger$.

11 J. Bouffard, B. K. Keitz, R. Tonner, G. Guisado-Barrios, G. Frenking, R. H. Grubbs and G. Bertrand, Organometallics, 2011, 30, 2617. Attempts to obtain a $\mathrm{SbCl}_{6}{ }^{-}$salt (see ref. 9) failed probably because of the occurrence of chlorination of $\mathrm{C}_{60}$ by $\mathrm{SbCl}_{5}$.

12 (a) H. Li, C. Risko, J. H. Seo, C. Campbell, G. Wu, J.-L. Brédas and G. C. Bazan, J. Am. Chem. Soc., 2011, 133, 12410; (b) J. IglesiasSigüenza and M. Alcarazo, Angew. Chem., Int. Ed., 2012, 51, 1523.

13 S. Y. Yang, X. F. Lin, C. K. Sun and D. C. Fang, THEOCHEM, 2007, $\mathbf{8 1 5}, 127$. Our calculation used a rather simplified BHandHLYP/6$31 \mathrm{G}(\mathrm{d})$ method to reduce its calculational cost.

14 However, the use of a large excess of $\mathbf{1}$ and $\mathrm{KPF}_{6}$ gave inseparable byproducts, e.g., bi- and multi-adducts or products due to the decomposition of the labile intermediate $2^{+}$.

15 Most 1,3-dipoar reactions of fullerene proceed with nucleophiles rather than electrophiles, except for the addition of ozone. See (a) R. Malhotra, S. Kumar and A. Satyam, J. Chem. Soc., Chem. Commun., 1994, 1339; (b) D. Heymann, S. M. Bachilo, R. B. Weisman, F. Cataldo, R. H. Fokkens, N. M. M. Nibbering, R. D. Vis and L. P. F. Chibante, J. Am. Chem. Soc., 2000, 122, 11473.

16 (a) X. Zhang and M. Takeuchi, Angew. Chem., Int. Ed., 2009, 48, 9646; (b) X. Zhang, T. Nakanishi, T. Ogawa, A. Saeki, S. Seki, Y. Shen, Y. Yamauchi and M. Takeuchi, Chem. Commun., 2010, 46, 8752; (c) T. Nakanishi, Y. Shen, J. Wang, H. Li, P. Fernandes, K. Yoshida, S. Yagai, M. Takeuchi, K. Ariga and D. G. Kurth, et al., J. Mater. Chem., 2010, 20, 1253; (d) S. S. Babu, H. Möhwald and T. Nakanishi, Chem. Soc. Rev., 2010, 39, 4021; (e) S. Santhosh Babu, A. Saeki, S. Seki, H. Möhwald and T. Nakanishi, Phys. Chem. Chem. Phys., 2011, 13, 4830. 